\title{
FICÇÃO ESPECULATIVA ESCRITA POR MULHERES NEGRAS
}

\author{
Waldson Gomes de Souza ${ }^{1}$ \\ Isadora Maria Santos Dias ${ }^{2}$
}

\begin{abstract}
RESUMO: No que diz respeito à ficção especulativa (fantasia, ficção científica e horror sobrenatural), o reconhecimento e as narrativas são dominadas por homens, e mais especificamente, homens brancos. Por isso é significativo analisar as produções literárias de mulheres negras, uma vez que em relação a elas há uma dupla opressão, por gênero e raça, limitando suas publicações e acesso a determinados espaços. O objetivo deste trabalho é analisar os romances Kindred: laços de sangue, de Octavia E. Butler, e Quem teme a morte, de Nnedi Okorafor. Em Kindred, a protagonista Dana vive nos Estados Unidos, durante a década de 1970, e é transportada para o século XIX, no período pré-Guerra Civil. Ela passa a vivenciar na pele a realidade da escravidão tendo como parâmetro seu conhecimento histórico. Já Quem teme a morte se passa em uma África futurista pós-apocalíptica e narra a jornada de Onyesonwu descobrindo ser possuidora de superpoderes que podem salvar a humanidade. A fundamentação teórica tem como base estudos de gênero e raça com foco nas especificidades das produções especulativas, bem como discussões sobre Afrofuturismo - movimento estético no qual as obras de Butler e Okorafor podem ser incluídas. A metodologia prevê leitura e fichamentos dos romances, a partir de uma análise comparativa que pretende articular os pontos de proximidade $e$ distanciamento na construção das duas narrativas. Concluindo, portanto, com considerações sobre a relevância das categorias gênero e raça nas análises das obras destas autoras.
\end{abstract}

PALAVRAS-CHAVE: ficção especulativa. mulheres negras. Octavia Butler. Nnedi Okorafor.

\section{INTRODUÇÃO}

No artigo Centro e margens: notas sobre a historiografia literária (2008), Rita Terezinha Schmidt argumenta sobre a formação da historiografia literária brasileira. Preocupando-se, essencialmente, com o modo pelo qual essa historiografia tem sido recontada e questionada pela crítica literária feminista, levando em consideração, assim, as ausências e apagamentos de pensadoras, críticas e escritoras mulheres.

De acordo com a autora, a constituição da literatura como cânone atrelado ao superior e inalcançável pela intelectualidade popular serve a um modo hegemônico de se pensar a literatura. E a supressão da existência e do trabalho intelectual de mulheres deixaria subentendido que mulheres não podem e/ou não devem ocupar espaços de intelectualidade. Daí a importância do trabalho de

\footnotetext{
${ }^{1}$ Graduado em Letras - Português do Brasil como Segunda Língua pela Universidade de Brasília, UnB, Brasil. Email: waldson.souza7@gmail.com

${ }^{2}$ Graduado em Português do Brasil Como Segunda Língua pela Universidade de Brasília, UnB, Brasil. Email: isadoras.unb@gmail.com
} 
resgate, recuperação e recriação de uma memória e narrativa literária nacional que desestabilize o discurso dominante.

Se há um processo de bloqueio em relação à produção literário-intelectual de mulheres, quando pensamos na produção de mulheres negras temos então um duplo silenciamento. Nos termos de Kimberlé Crenshaw (2002), as violências direcionadas a mulheres negras seriam atravessadas tanto por questões de gênero quanto raciais, dando origem a uma discriminação interseccional. Na qual "o que ocorre, em última instância, é que o peso combinado das estruturas de raça e das estruturas de gênero marginaliza as mulheres que estão na base" (CRENSHAW, 2002, p. 12).

Pensando numa historiografia literária nacional, autoras negras teriam seu total apagamento explicado por essa discriminação interseccional. É o caso de Rosa Egipcíaca (1719-1778), autora de Sagrada teologia do amor divino das almas peregrinas, tido como o mais antigo livro escrito por uma mulher negra na história brasileira; Auta de Sousa (1876-1901) poeta, da $2^{\text {a }}$ geração romântica, autora de Horto; e Maria Firmina dos Reis (1825-1917), autora de Úrsula, primeiro romance abolicionista da literatura brasileira.

E não é como se tais mecanismos de exclusão não estivessem em pleno funcionamento na atualidade. Escritoras, especialmente, escritoras negras sofrem sanções na criação, acesso e veiculação de suas obras devido a gênero e raça. Nos voltando para a análise da produção de ficção especulativa (termo guardachuva para os gêneros ficção científica, fantasia e horror sobrenatural) de mulheres negras teríamos uma tripla marginalização. Por gênero, raça e pela posição não canônica, desprestigiada da literatura especulativa no campo literário.

\section{AFROFUTURISMO}

A falta de representação negra na ficção especulativa reforça o questionamento que Mark Dery fez na década de 1990. Ele estranhava a pequena quantidade de autoras negras e autores negros na ficção científica, já que essa literatura constantemente aborda diferença, preconceito, o contato com o outro e diversos temas que são questões vividas pela população negra. Dery chamou de Afrofuturismo a ficção científica de autores negros. 
Neste trabalho, pensamos no Afrofuturismo como ficção especulativa de autoria negra com protagonismo negro e perspectivas não eurocêntricas, seguindo a definição proposta por Ytasha Womack (2013, p. 9, tradução nossa), que diz

\begin{abstract}
Tanto uma estética artística quanto uma estrutura para uma teoria crítica, - Afrofuturismo combina elementos da ficção científica, ficção histórica, ficção especulativa, fantasia, afrocentricidade e realismo mágico com crenças não ocidentais. Em alguns casos, é uma reelaboração total do passado e uma especulação sobre o futuro carregada de críticas culturais.
\end{abstract}

Para Charles R. Saunders (2000), ficção científica e fantasia são gêneros que oferecem ao público majoritário rotas de escape e janelas para o futuro, mas a falta de representação negra e repetição de estereótipos impedem que pessoas negras se identifiquem com essa literatura. Por outro lado, quando pessoas negras contam suas próprias histórias especulativas, encontramos representações que fogem do discurso hegemônico. O Afrofuturismo, enquanto movimento estético, tem a capacidade de mudar o passado, elevar a imaginação para além das convenções da realidade e criar outros parâmetros de expectativa para pessoas negras.

Mais do que trabalhar com protagonismo negro, o Afrofuturismo fornece perspectivas negras, nas quais os aspectos raciais são partes intrínsecas das obras, como é o caso dos dois romances que analisaremos neste trabalho.

\title{
ANÁLISE DAS OBRAS
}

Em Kindred: laços de sangue, de Octavia E. Butler, lançado em 1979, a experiência entrecruzada de raça e gênero é evidenciada pela narradora e protagonista Dana a partir da vivência de um período histórico distinto do seu. De modo inexplicável, a protagonista acaba viajando no tempo, da Califórnia da década de 1970 para uma Maryland escravista no século XIX. Não bastando os problemas enfrentados por uma mulher negra no período escravista, o motivo da viagem tempo-espacial de Dana se mostra ainda mais complicado. A missão da personagem é proteger a vida de um homem branco, que ela descobre ser seu antepassado. Sendo assim, a morte dele poderia resultar em um paradoxo no qual a própria Dana nunca existiu. 
Essa relação de completa desigualdade entre a protagonista e seu protegido, Rufus Weylin, é feita por ela própria, ao notar que era a pior guardiã possível, por ser "uma negra para cuidar dele em uma sociedade que via os negros como sub-humanos, uma mulher para cuidar dele em uma sociedade que via as mulheres como eternas incapazes" (BUTLER, 2017, p. 110). O centro da narrativa é portanto a conexão entre Dana e Rufus, mas é através do olhar de Dana para outras mulheres e homens negros escravizados que a história ganha complexidade.

Para além dos momentos nos quais a vida de Rufus corre perigo e precisa ser salva, a narrativa se estrutura em torno de Dana tentando sobreviver num tempo-espaço ao qual não pertence, mas do qual ela é fruto. É inegável que o eixo do romance gira em torno dos problemas que um sistema escravista traz para uma mulher negra de outro espaço-tempo.

Porém, é vivenciando a realidade das mulheres ao seu redor que Dana nos conta sua história. Seja na figura da senhora da casa grande, Margaret Weylin, descrita como uma dama, entediada, que não fazia serviço algum além de criticar o trabalho alheio e perturbar a todos (BUTLER, 2017, p. 151). Ou nas figuras de Alice, Sarah, Carrie e Tess, mulheres negras escravizadas que ocupam diferentes funções na narrativa e na experiência de Dana. Para a família Weylin, contudo, essas mulheres significam uma coisa só: propriedade.

Sobre diversas personagens, a branquitude representada nos Weylin tem uma narrativa uníssona, pois são escravas por eles compradas e por isso thes devem obediência. É o caso de Tess, personagem que teme deixar de ser sexualmente atrativa e ser forçada a trabalhar no campo; de Sarah, a "mãe preta", dona da cozinha, que cuida da casa e de todos, mas teve o direito de cuidar dos próprios roubado; de Carrie, filha de Sarah, que só está junto da mãe por ter deficiência e devido a isso ter menor valor; e de Alice, de quem Rufus Weylin não se envergonhava de estuprar, mas se envergonhava de amar por ser negra (BUTLER, 2017, p. 201).

É possível sim ler Kindred como uma história de ficção científica sobre escravidão, mas também é plausível reparar que, no fundo, Octavia E. Butler não está escrevendo sobre uma escravidão geral e pouco palpável. A partir da perspectiva de Dana, há um evidente esforço em situar e especificar a narrativa 
de mulheres negras. Os cinco episódios nos quais Dana viaja no tempo-espaço para salvar Rufus são o ponto de partida para as questões com as quais a protagonista precisa lidar. Para Dana, que por ser de outra época não corresponde às expectativas em relação a uma mulher negra do século XIX, é muito mais importante entender e se aproximar de pessoas negras para se manter viva do que de um senhor de escravos que, mesmo lhe devendo a vida, a trata como mero objeto.

Nesse mesmo sentido, no artigo "Only by Experience": Embodiment and the Limitations of Realism in Neo-Slave Narratives (2007), Sherryl Vint, analisa como esta obra de Octavia E. Butler se enquadraria e simultaneamente diferenciaria do gênero "narrativas neo-escravistas", do inglês neo-slave narratives, que se refere ao gênero literário no qual as narrativas sobre escravidão são reimaginadas e não corroboram com obras históricas hegemônicas produzidas por autores brancos. Na perspectiva de Sherryl Vint, tanto este romance quanto Amada (1987), de Toni Morrison, se apropriariam de fatos históricos sobre a escravidão para recriar e rememorar estas narrativas a partir da corporalidade de mulheres negras.

Especificamente em Kindred, a revisão histórica apresentada pela perspectiva, em primeira pessoa, da protagonista, coloca em questão as narrativas históricas comuns e dominantes sobre a escravidão, se aproximando das narrativas neo-escravistas ou neo-históricas. Mas, além disso, com a utilização da viagem no tempo como elemento mobilizador de espaços e temporalidades na narrativa, Butler estaria reconfigurando simultaneamente 0 gênero das neo-slave narratives e o da ficção científica.

Esta reconfiguração pode ser percebida quando, Após regressar para sua casa e tempo origem, em 1976, Dana diz:

\footnotetext{
Li livros sobre escravidão, ficção e não ficção. Li tudo o que tinha na casa, por menos relacionado ao assunto que fosse, até mesmo $E O$ Vento Levou, ou parte dele. Mas sua versão de negrinhos felizes foi demais para mim [...] Os livros me deixaram deprimida, assustada [...] Como os nazistas, os brancos pré-guerra entendiam um bom tanto de tortura, um bom tanto a mais do que eu queria entender (BUTLER, 2017, p. 188-189).
}

Mesmo que ela, uma mulher do século XX, tenha conhecimento histórico sobre a escravidão, isso não é suficiente para que ela saiba sempre agir de 
acordo com o período para o qual é transportada. No geral, não há acolhimento para Dana no tempo-espaço dos Weylin, já que para escravizados, como Alice, ela é uma "preta branca" (BUTLER, 2017, p. 257) por ter conhecimentos de escrita e medicina. Para os senhores da casa, esses conhecimentos significam afronta, como dito por Rufus: "Tratei você como se fosse melhor que os pretos comuns! Vejo que errei [...] você se acha branca! [...] não sabe seu lugar, parece um animal selvagem (BUTLER, 2017, p. 263)".

Por passar a viver em contínuo estado de alerta, sujeita a uma mudança brusca em relação a tempo e espaço, Dana ocupa um entre-lugar na narrativa. Onde, no século XIX, ela é uma "preta branca" por conhecer e falar como brancos, que "se vestia como homem" por usar calças jeans e que "não sabia seu lugar" por não obedecer piamente aos costumes e ordens da família Weylin. E no século XX, Dana se narra como alguém permanentemente afetada pela experiência de retorno ao período escravista: "Toquei a cicatriz que a bota de Tom Weylin havia deixado em meu rosto, toquei minha manga do lado esquerdo. - Eu sei - repeti - Porque eu quis vir aqui afinal? Era de se imaginar que eu já vivi o passado o suficiente (BUTLER, 2017, p. 424)". Como se a própria personagem tivesse dificuldade em se encaixar no seu espaço-tempo de origem.

Fazendo a relação entre a personalidade de Dana e o modo como a corporalidade dela se relacionam e modificam ao longo da narrativa pela violência, Sherryl Vint (2007, p. 249, tradução nossa) argumenta que

\begin{abstract}
A punição corporal, ameaçadora e real, é uma tecnologia disciplinar que produz subserviência. Embora a plantação não tenha a elegância simbólica do panóptico, ela é, não obstante, um espaço de vigilância e poder de normalização. Como observa Foucault, o poder disciplinar não apenas controla ou restringe, mas na verdade produz o sujeito. Assim, as experiências do corpo de Dana são capazes de moldar e mudar sua "essência" interior, desmentindo a realidade de qualquer entidade desse tipo.
\end{abstract}

Ainda de acordo com Vint (2007), em Kindred, além de acompanharmos a trajetória de Dana se descobrindo um corpo passível de ser violentado, há uma forte explicitação de cenas violentas, contra Dana e contra as demais pessoas escravizadas. Não são raras cenas de estupro, assédio moral e açoite. Mas, são principalmente as cenas de assédio e violência sexual as mais frequentes, ou seja, as violências às quais mulheres escravizadas eram constantemente 
sujeitadas. E essas descrições explícitas de violências sexuais distinguiriam este romance das narrativas neo-escravistas ou neo-históricas, uma vez que o açoite é mais comumente retratado neste gênero ficcional do que violências sexuais, por exemplo. A continuidade dessa exacerbação da violência como modo de revisitar e questionar ocorrências históricas ou culturais pode ser notada na obra de outra autora de ficção especulativa, Nnedi Okorafor.

Em Quem teme a morte (2010), Nnedi Okorafor constrói uma narrativa que mistura fantasia e ficção científica e é ambientada em uma África futurista. Não há uma preocupação inicial em definir o país ou o ano nos quais a narrativa é ambientada, mas nas últimas páginas descobrimos que o lugar onde a história se passou "costumava ser parte do Reino do Sudão" (OKORAFOR, 2014, p. 404). O universo ficcional de Okorafor é dividido entre Okeke e Nuru, respectivamente pessoas negras e pessoas de pele mais clara, fenótipo árabe. Okeke vivem majoritariamente no leste, região mais desértica onde não vivem os Nuru e há mais escassez de recursos naturais, principalmente água. Nuru vivem no Oeste subjugando e escravizando Okeke, esta região possui mais recursos e é conhecida pelos seus sete rios. Nuru devastam e violentam a população Okeke que se vê obrigada a migrar e se afastar cada vez mais para o leste.

Nesse romance, o espaço da narrativa é o deserto, mas isso não significa de modo algum sinônimo de vazio e monotonia, na história de Onyesonwu (Onye) o deserto é amplamente povoado e disputado. De acordo com o narradoraprotagonista o deserto significa lar, aconchego e as memórias da infância, em que

\footnotetext{
por seis anos Najeeba criou Onyesonwu sozinha no deserto. Ela cresceu e se tornou uma criança feliz. Amava a areia, o vento e as criaturas do deserto. Embora Najeeba pudesse apenas sussurrar, ria e sorria sempre que Onyesonwu gritava. Quando gritava as palavras que Najeeba a ensinara, a mãe a abraçava e a beijava. Foi assim que a criança aprendeu a usar a voz sem nunca ter ouvido alguém falar (OKORAFOR, 2014, p. 34).
}

Para além do aspecto afetivo trazido pela protagonista, que sendo Ewu ocupa o lugar da marginalização não sendo bem-vinda em nenhuma cidade, o deserto de Okorafor é diverso, plural. Além das divisões entre povos ou etnias Nuru, Okeke, Ewu, Noah e Vah (Povo Vermelho), o romance também nos mostra distintas cidades e vilarejos como Jwahir, Diliza, Gadi, Banza, Papa Shee, Ssolu e o reino dos Sete Rios e suas sete grandes cidades, Chassa, Durfa, Suntown, 
Sahara, Ronsi, Wa-wa e Zin. O deserto funcionando, portanto, como enquadramento e peça fundamental na composição da narrativa, já que cada cidade tem seu próprio funcionamento econômico e cultural, a depender do domínio Nuru ou Okeke. Onye ressalta esses fatores ao passar por uma delas:

Banza era uma cidade Okeke guiada pela arte e cultura. Não era velha
como Jwahir. As feridas de Banza ainda estavam frescas. Com o passar
dos anos, Banza aprendeu a usar o mal para criar o bem. Os fundadores
da cidade transformaram sua dor em arte, cuja produção e venda se
tornou o ponto principal da cultura de Banza (OKORAFOR, 2014, p.215).

Nessa perspectiva, na qual o espaço ficcional não funciona apenas como pano de fundo, mas como parte integrante e modificadora do cotidiano e das identidades das personagens, o deserto, suas tradições e desafios são ponto de partida para muitas das questões relacionadas a gênero, sexualidade, raça e corporalidade no romance.

Ademais, as diferenças raciais são importantes na composição do romance, principalmente no desenvolvimento da protagonista que ocupa um meio termo entre Okeke e Nuru. Onyesonwu narra o livro e lida com o fato de ser Ewu, termo usado para definir aqueles que nasceram da relação entre Okeke e Nuru. Essa relação em quase todos os casos ocorre por meio de estupros cometidos por homens Nuru contra mulheres Okeke e "as pessoas acreditam que os nascidos Ewu em determinado momento se tornam violentos. Acreditam que um ato de violência só pode gerar mais violência (OKORAFOR, 2014, p.36)". Essa origem violenta está marcada na pele de Onye, que como todo Ewu possuía olhos, cabelos e pele da cor de areia, a tonalidade mais clara em comparação com o tom escuro dos Okeke é uma lembrança constante do estupro que sua mãe sofreu. E motivo pelo qual Onye é discriminada.

Onye odeia seu pai biológico, Daib, por todo o sofrimento que ele causou a mãe dela. Daib é um mago poderoso que planeja exterminar os Okeke e matar Onye no processo. Com seu pai significando uma ameaça para todos, Onye inicia uma jornada em direção ao oeste para enfrentá-lo, acompanhada de cinco amigos: Diti, Binta, Luyu, Fanasi e Mwita. Mwita, que na verdade é namorado de Onye, merece uma atenção maior em nossa análise pelo fato de também ser Ewu e iniciado em magia como Onye. O relacionamento de Onye com Mwita é importante porque significa para a protagonista não só noção de pertencimento e 
reconhecimento, já que eles possuem o mesmo tom de pele, mas também a capacidade de ser amada. Sentimento que só havia recebido de sua mãe e de seu pai adotivo.

A sociedade de Onye é fortemente marcada por construções de expectativas em relação aos papéis de gênero. Existe um ritual de remoção clitoriana pelo qual as garotas que vivem em Jwahir são submetidas. A prática não é obrigatória, mas acredita-se que "não fazer circuncisão aos onze anos gera má-sorte e vergonha para a família" (OKORAFOR, 2014, p. 38). Uma tradição de dois mil anos que tem sua função questionada por Onye, mas ela acaba decidindo participar porque não quer possuir mais uma característica de distinção social para somar ao fato de ela ser Ewu. O ritual também resulta na construção de um laço afetivo entre Onye, Binta, Diti e Luyu, já que "a maioria das garotas que passavam juntas pelo rito dos onze anos, embora "atadas" umas às outras, não permaneciam assim algum tempo depois. Mas a mudança foi natural para nós. Já tínhamos nossos segredos. E era só o começo (OKORAFOR, 2014, p. $55)$ ".

Ainda sobre papéis de gênero e tradição, mesmo a relação entre Mwita e a protagonista se mostra, por vezes, afetada pelas expectativas dele em relação às ocupações destinadas às mulheres. O companheiro de Onye não se conforma, por exemplo, com o fato de não ter sido aceito como mago, e com fundamento tradicionalista e sexista, argumenta que "eu deveria ser o feiticeiro e você deveria ser a curandeira. Foi sempre assim entre um homem e uma mulher (OKORAFOR, 2014, p. 273)".

Aprofundando cruzamentos de sexualidade, saúde, corporalidade, raça e gênero, no texto The Unbearable Burden of Culture: Sexual Violence, Women's Power and Cultural Ethics in Nnedi Okorafor's Who Fears Death (2015), Esther L. Jones disserta sobre a sexualidade como tema central em Quem teme a morte. Por entender que a sexualidade das personagens mulheres na obra é fonte de controle e domínio. Tensionando questões em torno das discussões sobre extirpação clitoriana e estupro como arma e tática de guerra, Esther L. Jones, relaciona o texto ficcional de Okorafor com as notícias e práticas que deram origem ao romance, ocorridas em territórios como Ruanda, Serra Leoa e Sudão. E constata o seguinte: 
Okorafor faz com que Onyesonwu demonstre as maneiras pelas quais o estupro militarizado e a mutilação genital feminina formam os dois lados da moeda da violência sexual exercida contra as mulheres dessa cultura futurista. Nascida de estupro militarizado, ela funciona como um "prisma pela diferença", dentro de uma cultura que não oferece espaço para sua existência. E por isso, ela deve estabelecer sua própria razão de ser. Em nome de uma comunidade, a violência que permeia todos os estágios da vida de Onyesonwu controla a sexualidade das mulheres para manipular o senso comum. Os esforços dela para ganhar normalidade e pertencer como mulher e como Ewu, apontam para um problema social que muitas vezes age contra as capacidades sexuais e reprodutivas das mulheres (JONES, 2015, p. 77, tradução nossa).

Ainda que distante de uma narrativa neo-histórica como Kindred, no mesmo sentido de Vint, Jones ressalta, em Quem teme a morte, a importância e a vulnerabilidade do corpo a violências, principalmente sexuais, nas narrativas de mulheres negras ou não-brancas. Obras nas quais se torna perceptível a preocupação em trazer questões de gênero e raça como marcadores de diferença, o que é fundamental nas produções de autoras afrofuturistas.

Em relação ao gênero especulativo, ambas as obras transitam entre a fantasia e a ficção científica. Kindred aborda uma temática típica da ficção científica, mas nunca é explicado como Dana faz suas viagens temporais, o mais provável é que seja uma força sobrenatural direcionada para o fantástico. Quem teme a morte, por sua vez, se passa em um futuro pós-apocalíptico, no meio do deserto. Há destruição, há escassez de recursos naturais, mas há também tecnologias remanescentes.

Octavia E. Butler mostrou que a viagem no tempo, um dos temas mais trabalhados da ficção científica, não funciona da mesma forma para pessoas negras. Para além dos paradoxos temporais, personagens brancos encontram aventuras emocionantes com diversas possibilidades ao visitar outras épocas passadas. Mas a protagonista de Kindred, uma mulher negra, se depara com a violência e a opressão da escravidão ao ser transportada para o século XIX, no período pré-Guerra Civil. Angela Davis (2016, p. 180) diz que "a escravidão se sustentava tanto na rotina do abuso sexual quanto no tronco e no açoite", sendo o abuso sexual uma violência sistematicamente imposta às mulheres. Para Davis, a mulher negra era vista como desprovida de gênero quando realizava serviços braçais, no sentido de precisar desempenhar as mesmas tarefas que os homens, sem divisão distintiva. Mas o gênero voltava a ser um fator relevante quando o 
homem branco queria demonstrar seu poder através do acesso ao corpo das mulheres negras.

Okorafor, por sua vez, traz à luz os possíveis efeitos de violências e das memórias relacionadas a elas, mesmo que não vividas e "apenas" compartilhadas, na subjetividade de sua personagem. Pensando no estupro como uma forma de violência física e discursiva perpetrada contra mulheres, que em contexto de guerra/disputas é usada como arma para intimidar e subjugar.

Como inicialmente mencionado, Centro e margens: notas sobre a historiografia literária (2008), de Rita Terezinha Schmidt, explicita o fato de que a reconstrução e recuperação da memória e da produção de mulheres em literatura tem sido trabalho da crítica feminista. Poderíamos, então, ler as narrativas de Onye e Dana como esforços no mesmo sentido do proposto por Schmidt (2008). Com a diferença de que o feminismo construído a partir destas personagens estaria justamente se deslocando de uma ideia universal de mulher, dizendo especificamente sobre a experiência de mulheres negras.

Em Kindred, essa diferença pode ser claramente encontrada na relação entre Margaret Weylin e as mulheres negras escravizadas pela família dela. Mesmo a personagem sendo descrita como a senhora branca entediada, que a única ocupação é mandar e criticar o trabalho alheio e que sofre com a indiferença do marido, Margaret Weylin não se faz mais suave ou humana em relação às mulheres negras por conta de seu próprio sofrimento causado pela condição subalterna de mulher.

$\mathrm{Na}$ medida em que seu sofrimento é diferente do das mulheres a sua volta, e somado ao fato de que a senhora Weylin sequer as percebe como humanas e mulheres, não haveria, portanto, uma união pela condição de mulher. E sim separação causada por questões de raça, na qual pessoas negras, e principalmente mulheres, não tem humanidade.

Se em Kindred essa marcação da diferença entre mulheres brancas e mulheres negras pode ser mais facilmente detectada, em Quem teme a morte essa diferenciação é um tanto mais sútil. Em Kindred é latente o discurso hegemônico de uma branquitude em relação ao período histórico, assim como também é latente o contradiscurso e a resistência a essa hegemonia. Em Quem teme a morte, entretanto, o discurso parece se fazer no sentido de mostrar que 
mesmo dentro de grupos e situações não hegemônicas há diversidade e embates internos. Onye, ao lidar com a discriminação dentro de sua própria comunidade que também é oprimida, pode ser lida como uma declinação dessa ideia dicotômica de poder.

Seguindo essa lógica, a história de Onye poderia ser associada a uma noção mais relacional de poder. Na qual o poder não é apenas unilateral ou simétrico, mas surge de pontos diversos, em conflitos contínuos. Ao ser discriminada por sua pele clara, numa sociedade que entende e vive a dominação, essa personagem estaria apontando para a capacidade de oprimidos também exercerem níveis de poder. E em alguma medida, se tornarem opressores.

A discussão possível a partir da narrativa de Onye caminharia para uma complexificação da ideia de opressão, indo num entendimento mais foucaultiano de poder, no qual

a condição de possibilidade do poder, em todo caso, o ponto de vista que permite tornar seu exercício inteligível até em seus efeitos mais "periféricos" e, também, enseja empregar seus mecanismos como chave de inteligibilidade do campo social não deve ser procurada na existência de um ponto central, num foco único de soberania de onde partiriam formas derivadas e descendentes; é o suporte móvel das correlações de força que, devido a sua desigualdade, induzem continuamente estados de poder, mas sempre localizados e instáveis (FOUCAULT, 2017, p. 101).

Assim é cabível ler Dana e Onye como personagens pensadas para marcar e trabalhar a questão da diferença. Diferença encarnada, que se faz por marcas físicas e psicológicas violentas deixadas nos corpos dessas personagens.

Tanto em Kindred quanto em Quem teme a morte há um ancoramento nas histórias contadas e vividas por mulheres. É a partir dos traumas, esperanças e memórias delas que as protagonistas dizem sobre si. Essa rede é representada, no romance de Okorafor, nas figuras da mãe Najeeba, das amigas Luyu, Diti e Binta. Já na história de Butler, se misturam, principalmente, nas figuras de Alice e Sarah. A rede de mulheres negras, em ambas as narrativas, funciona não como simples pano de fundo, mas sim como alicerce de narrativas. Subjetivando e marcando profundamente as protagonistas. 


\section{CONCLUSÃO}

Se para uma narrativa afrofuturista pensar negritude e raça é essencial, em obras produzidas por mulheres nesse movimento, é igualmente relevante considerar gênero como categoria significante e representativa. Uma vez que para mulheres negras o gênero é modificado e atravessado por questões raciais e vice-versa, analisar as construções dessas mulheres desconsiderando alguma dessas categorias é analisar produção e autoria de maneira insuficiente, negando a constituição histórico-social de suas identidades.

Se em Kindred, Octavia E. Butler localiza a posição de mulheres negras em relação a uma hegemonia branca, em Quem teme a morte, Nnedi Okorafor mostra que há diferenças também entre mulheres e comunidades negras ou nãobrancas. Há, portanto, uma desvelada preocupação de ambas as autoras em salientar a complexidade e diversidade da experiência de mulheres negras, além de marcar o fato de que mulheres negras, e consequentemente seus corpos, estão sujeitas a violências específicas.

Ainda que produzindo ficção científica em momentos históricos diferentes, é contínua e premente a relevância da categoria de raça e gênero nas obras de Butler e Okorafor. O que, talvez, indique não apenas a necessidade de uma crítica feminista que afirme o problema do apagamento de mulheres no campo literário. Mas também a necessidade de uma crítica feminista negra que se pronuncie sobre o apagamento da produção literária de mulheres negras. Entendendo que marcar e diversificar a categoria mulher não significa, de modo algum, separatismo, e sim o reconhecimento e legitimação de experiências variadas.

\section{SPECULATIVE FICTION WRITTEN BY BLACK WOMEN}

ABSTRACT: In relation to speculative fiction (fantasy, science fiction, and supernatural horror),
recognition and narratives are dominated by men, and more specifically, white men. That is why it
is significant to analyze the literary productions of black women, since in relation to them there is a
double oppression, by gender and race, limiting their publications and access to certain spaces.
The objective of this work is to analyze the novels Kindred, by Octavia E. Butler, and Who Fears
Death, by Nnedi Okorafor. In Kindred, the protagonist Dana lives in the United States during the
1970 s and is transported to the nineteenth century in the pre-Civil War period. She begins to
experience the reality of slavery based on her historical knowledge. On the other hand, Who Fears
Death takes place in a post-apocalyptic futuristic Africa and tells the journey of Onyesonwu
discovering to have superpowers that can save the humanity. Our theoretical foundation is based
on gender and race studies focusing on speculative productions specificities, as well as 
discussions on Afrofuturism - aesthetic movement in which Butler and Okorafor works can be included. The methodology includes reading and writing of the novels, based on a comparative analysis that aims to articulate the points of proximity and distance in the construction of the two narratives. Concluding with considerations on the relevance of the categories gender and race in the analyzes of the works of these two authors.

KEYWORDS: speculative fiction. black women. Octavia Butler. Nnedi Okorafor.

\section{REFERÊNCIAS}

BUTLER, Octavia E. Kindred: Laços de sangue. Trad. Carolina Caires Coelho. São Paulo: Editora Morro Branco, 2017.

CRENSHAW, Kimberlé $W$. A intersecionalidade na discriminação de raça e gênero. In: VV.AA. Cruzamento: raça e gênero. Brasília: Unifem, 2004. Disponível em: <http://www.acaoeducativa.org.br/fdh/wpcontent/uploads/2012/09/KimberleCrenshaw.pdf> Acesso em: 19 de fevereiro de 2018.

DAVIS, Angela. Mulheres, raça e classe. São Paulo: Boitempo, 2016.

DERY, Mark. Black to the Future: interviews with Samuel R. Delany, Greg Tate, and Tricia Rose. In: DERY, Mark (ed.). Flame Wars: The Discourse of Cyberculture. Durham, NC: Duke University Press, 1994. p. 179-222.

FOUCAULT, Michel. História da Sexualidade I: A Vontade de Saber. $5^{\text {a }}$ edição: Rio de Janeiro/São Paulo, Paz e Terra, 2017.

JONES, Esther L. The Unbearable Burden of Culture: Sexual Violence, Women's Power and Cultural Ethics in Nnedi Okorafor's Who Fears Death In: Medicine and ethics in Black women's speculative fiction. Nova York: Palgrave Macmillan, 2015, p. 64-90.

OKORAFOR, Nnedi. Quem teme a morte. Trad. Mariana Mesquita. São Paulo: Geração Editorial, 2014.

SAUNDERS, Charles R. Why blacks should read (and write) science fiction. In: THOMAS, Sheree R. (ed.). Dark Matter: a century of speculative fiction from the african diaspora. Nova York: Warner Books, 2000. p. 398-404.

SCHMIDT, Rita Terezinha. Centro e margens: notas sobre a historiografia literária. Brasília: Revista Estudos de Literatura Brasileira Contemporânea, v. 32, p. 127-141, 2008.

VINT, Sherryl. "Only by Experience": Embodiment and the Limitations of Realism in Neo-Slave Narratives. Science Fiction Studies, Vol. 34, No. 2, p. 241-261, 2007.

WOMACK, Ytasha L. Afrofuturism: the world of black sci-fi and fantasy culture. Chicago: Lawrence Hill Books, 2013.

Data da Submissão: 29/04/2018

Data da Aprovação: 24/07/2018

Revista de Letras JUÇARA, Caxias - Maranhão, v. 02, n. 01, p. 298 - 311, jul. 2018 | 311 